\title{
Widespread Long-term Gene Transfer to Mouse Skeletal Muscles and Heart
}

\author{
Leslie D. Stratford-Perricaudet, * Iman Makeh, ${ }^{*}$ Michel Perricaudet, ${ }^{*}$ and Pascale Briand* \\ ${ }^{*}$ Institut Gustave Roussy, Centre National de la Recherche Scientifique, UA 1301, 94805 Villejuif, France; and ${ }^{\ddagger}$ Institut Cochin de \\ Génétique Moléculaire, Institut National de la Santé et de la Recherche Médicale, CJF 9003, 75014 Paris, France
}

\begin{abstract}
Successful treatment of muscular disorders awaits an adapted gene delivery protocol. The clinically applicable technique used for hematopoietic cells which is centered around implantation of retrovirally modified cells may not prove sufficient for a reversal of phenotype when muscle diseases are concerned. We report here efficient, long-term in vivo gene transfer throughout mouse skeletal and cardiac muscles after intravenous administration of a recombinant adenovirus. This simple, direct procedure raises the possibility that muscular degenerative diseases might one day be treatable by gene therapy. ( $J$. Clin. Invest. 1992. 90:626-630.) Key words: adenovirus • gene therapy $\bullet \beta$ galactosidase $\bullet$ muscular disease $\bullet$ eukaryotic viral vector
\end{abstract}

\section{Introduction}

The first genetic disorders amenable to gene transfer-based treatment will be monofactorial diseases. The vast array of target tissues translates the need for the development of appropriate, efficient gene transfer vehicles. The ability of retroviruses to integrate into the host genome has led to their use in ex vivo treatment protocols. Because those cell types capable of withstanding extraction, in vitro manipulation, and, finally, reimplantation are quite limited, other strategies need to be explored. Furthermore, the requirement retroviruses have for host cell proliferation constitutes an important drawback of such vectors and limits their applicability. Many targets relevant to human disease (liver, lung, muscle, neurons) will require other means of gene transfer.

Efficient and long-term expression of genes adenovirally transduced has recently been reported in hepatocytes and bronchial epithelium of animals (1-3), showing that the adenoviral vector is capable of transferring genes to nondividing or slowly proliferating cells. To investigate other potential targets for recombinant adenoviral vectors, we have constructed a recombinant adenovirus expressing a nuclearly targeted reporter enzyme (Ad.RSV $\beta$ gal). The rapid in situ detection of the nuclearly targeted $\beta$-galactosidase allows an unambiguous and precise appreciation of adenoviral-mediated gene transfer $(4,5)$.

Address correspondence to Leslie D. Stratford-Perricaudet, Institut Gustave Roussy, 39 rue Camille Desmoulins, 94805 Villejuif, France. Received for publication 13 January 1992 and in revised form 7 April 1992.

\section{J. Clin. Invest.}

(C) The American Society for Clinical Investigation, Inc.

0021-9738/92/08/0626/05 \$2.00

Volume 90, August 1992, 626-630

\section{Methods}

Construction of recombinant plasmid pAd.RSVBgal. The pAd.RSV$\beta$ gal is a pML-2 derivative where the nls lacZ gene with the SV40 early region polyadenylation signal $(5,6)$ driven by the Rous sarcoma virus long terminal repeat (RSV LTR) ${ }^{1}$ is inserted downstream of 1.3 map units (mu) (PvuII site) from the left end of the adenovirus type 5 (Ad5) genome. The reporter gene is followed by mu 9.4-17 (BglII-HindIII fragment) of Ad5 to allow homologous recombination with the adenoviral genome for the generation of the recombinant adenovirus (Fig. 1).

Construction of recombinant adenovirus Ad.RSVBgal. The recombinant adenovirus was constructed by in vivo homologous recombination (7) in 293 cells (8) between plasmid pAd.RSV $\beta$ gal and Ad d1327 (9) genomic DNA. Briefly, 293 cells were cotransfected with $5 \mu \mathrm{g}$ of linearized pAd.RSV $\beta$ gal and $5 \mu \mathrm{g}$ of the large ClaI fragment (2.6-100 $\mathrm{mu}$ ) of Ad5 DNA. After overlaying with agar and incubation for $10 \mathrm{~d}$ at $37^{\circ} \mathrm{C}$, plaques containing recombinant adenovirus were picked and screened for nuclear $\beta$-galactosidase activity. The recombinant virus was propagated in 293 cells and purified by cesium chloride density centrifugation. Titers of the viral stocks were determined by plaque assay using 293 cells.

Injection of mice. 2 - to 5 -d-old and adult $(2 \mathrm{mo})$ mice (C57BL6 $\times$ DBA) were injected either intravenously (iv) or intramuscularly (im) (quadriceps) with $20-40 \mu$ l of highly purified recombinant adenovirus, Ad.RSV $\beta$ gal $\left(10^{11}\right.$ plaque-forming units $\left.[\mathrm{pfu}] / \mathrm{ml}\right)$.

Escherichia coli $\beta$-galactosidase assay. Organs from killed animals were fixed in $4 \% p$-formaldehyde in PBS for $30 \mathrm{~min}$. After rinsing they were incubated overnight at $30^{\circ} \mathrm{C}$ in X-gal solution ( $\left.2 \mathrm{mM}\right)(6)$. Whole specimens were flash frozen in isopentane in liquid nitrogen and mounted in OCT compound (Miles Laboratories Inc., Naperville, IL) for cryosectioning. Sections (10 $\mu \mathrm{m}$ thick) were fixed $10 \mathrm{~min}$ in $p$-formaldehyde as described for organs, rinsed, and incubated with X-gal substrate. Sections were then counterstained with hematoxylin and eosin according to standard methods. Muscle was dissociated after whole organ staining to obtain isolated myofibers that were then counterstained with hematoxylin and eosin. Urine and fecal matter were collected at $2 \mathrm{~h}$ or $22 \mathrm{~d}$ after iv injection and exposed to 293 cells. After 24 $h$ of incubation at $37^{\circ} \mathrm{C}$ the cells were fixed and stained with X-gal solution.

DNA analysis of animals. The heart, lung, liver, and quadricep muscle from mice iv-injected with the recombinant adenovirus Ad.RSV $\beta$ gal were minced into liquid $\mathrm{N}_{2}$ and ground with a mortar and pestle. Total cellular DNA was prepared as described (10) and $10 \mu \mathrm{g}$ of either undigested or HindIII-digested DNA was subjected to electrophoresis in a $0.8 \%$ agarose gel. Southern blot analyses (Fig. $4 \mathrm{~A}$ ) were performed using either a Sall-BamHI fragment containing LacZ from pGEM-nlsLacZ (6), or a fragment from the pAd.RSV $\beta$ gal plasmid containing the RSV promoter and the upstream adenovirus sequences (Fig. $4 \mathrm{~B}$ ) to screen for the presence of the recombinant adenovirus.

1. Abbreviations used in this paper: Ad5, adenovirus type 5; DMD, Duchenne muscular dystrophy; mu, map units; pfu, plaque-forming units; RSV LTR, Rous sarcoma virus long terminal repeat. 

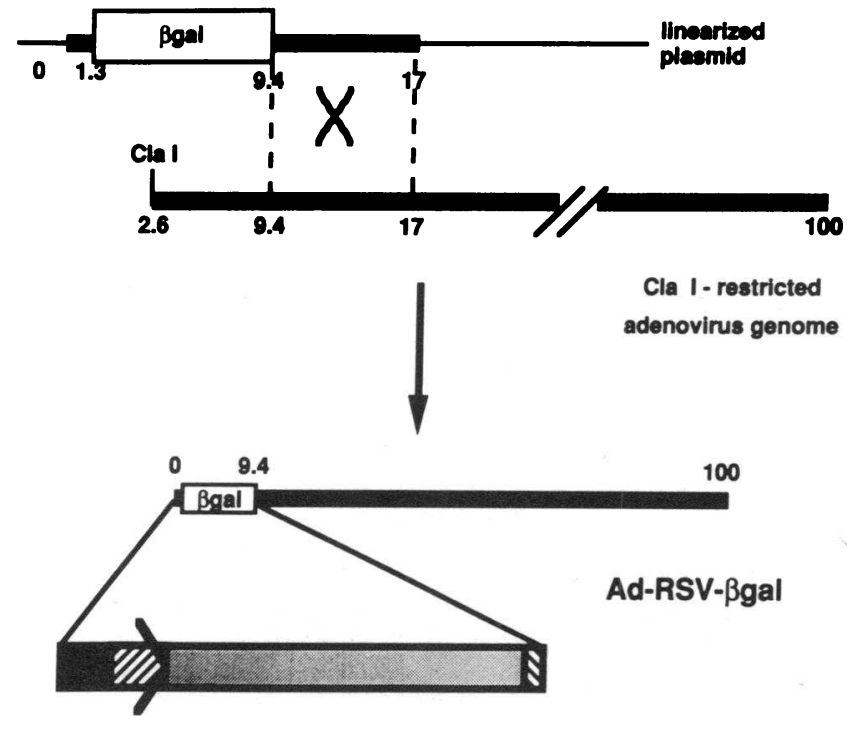

$1 \mathrm{mu}=360 \mathrm{bp}$

Figure 1. Generation of recombinant adenovirus, Ad.RSV $\beta$ gal, by in vivo recombination. The recombinant adenovirus was constructed through homologous recombination between plasmid pAd.RSV $\beta$ gal and the Ad5 genome. Shown also is an enlargement of the insert. The adenoviral sequences are depicted by $m$. The nlslac $Z$ gene $₫$ is controlled by the RSV LTR a and possesses the early mRNA polyadenylation signal from SV40

\section{Results}

Generation of the recombinant adenovirus, Ad.RSVBgal. Ad.RSV $\beta$ gal is a recombinant adenovirus that constitutively expresses $\beta$-galactosidase targeted to the nuclei of infected cells. The nls lacZ coding sequence with the SV40 early region 3 '-end processing signal and under the control of the RSV LTR was inserted into Ad dl327 in place of Ela and Elb (mu 1.3-9.4). Fig. 1 depicts the construction of the recombinant virus. Plaques resulting from the transfection of 293 cells were screened for $\beta$-galactosidase activity. Virus was amplified on 293 cells. The recombinant virus is replication incompetent due to its deletion for the E1 genes.

Expression of the transferred gene in mice injected as neonates. Neonatal mice were intravenously injected with the Ad.RSV $\beta$ gal recombinant virus, and gene transfer was assessed by histochemical staining for $\beta$-galactosidase activity in various tissues. The extent of blue staining reveals that a substantial percentage of cells within different tissues are infected. Positive perinuclear staining was systematically observed in many organs such as lung, liver, intestine, heart, and skeletal muscle (Fig. 2, $A-F$ ) of each of the four individual mice killed at $15 \mathrm{~d}$ after iv injection.

The exciting implications of efficient gene transfer into myocytes led us to characterize transduction to these cells in particular. Gross examination of the intact heart as well as skeletal muscles from the experimental animals reveals the impressive efficiency of gene transfer after only a single injection of the recombinant adenovirus (Fig. 2, $C, D$, and $F$ ). Because the intravenous route was used, the viral vector is not concentrated in any one area of the muscle tissue, and dispersion is favored. Histochemical staining of muscle leads to large patches of blue throughout. Approximately $0.2 \%$ of cardiac cells have undergone gene transfer after iv injection of $10^{9} \mathrm{pfu}$ of virus.

Expression of the transferred gene in both cardiac and skeletal muscle was found to be remarkably stable since monthly killed injected animals displayed $\beta$-galactosidase activity in these tissues throughout the 12-mo period of the experiment. Importantly, gene expression was sustained, although the proportion of blue cells in these muscle tissues seemed to decrease after the 10th month after injection.

Analysis of isolated fibers demonstrates the extent of dissemination of the transferred gene. A single fiber can show multiple "centers of expression" (Fig. 3). Each consists of a darkly stained central nucleus surrounded by nuclei forming a gradient of blue. These centers most probably result from independent local infections by the adenoviral vector. The number of colored nuclei in any one cluster was found to vary from 10 to 60 . The use of a nuclearly targeted marker is informative as to the degree of infection of multinucleated cells of this morphology.

Expression of the transferred gene in mice injected as adults. As to the distribution of the virus, results similar to those obtained in mice injected as newborns were found after intravenous inoculation of adults. It is apparent, however, that the injection of $10^{9} \mathrm{pfu}$ of virus leads to less efficient gene transfer in the larger adult mice. Intramuscular injections were also performed and histochemical staining at 21 days after injection revealed that the infection was circumscribed to the point of injection, as fibers with blue nuclei could only be detected within a $1-\mathrm{cm}$ area. Moreover, the absence of blue staining in other tissues (lung, liver, intestine) reveals a very limited diffusion of the virus when the intramuscular route is chosen.

Status of the viral DNA. Southern blot analysis of DNA from different tissues of an experimental animal indicates the presence of the adenovirus genome in a wide variety of organs (Fig. $4 A$ ). The detection of a DNA fragment corresponding to the left end of the recombinant viral genome indicates that the viral DNA is present as a linear form in the tissues infected $10 \mathrm{~d}$ previously (Fig. $4 \mathrm{~B}$ ). Moreover, the detection of a unique and intense band corresponding to $35.5 \mathrm{~kb}$ at $3 \mathrm{mo}$ after injection reveals that the viral DNA remains extrachromosomal (Fig. 5). The absence of a detectable smear rules out the possibility that integration events occurred with high frequency. Clearly, the sensitivity of the Southern blot does not allow a fair appreciation of gene transfer as does the in situ detection of the $\beta$-galactosidase activity. In this respect, it is reasonable that the estimation of a $0.2 \%$ transfer to the heart (based on staining) is compatible with the difference in intensity seen with the transgenic mouse DNA control (which harbors one copy of a LacZ gene per cell) (Fig. $4 \mathrm{~A}$ ). The incapacity to detect a band in the heart 12 mo after injection is in agreement with the decrease in the number of blue cells observed at this time.

\section{Discussion}

Gene therapy relevant to muscular diseases is especially hindered by the unsolved problem of the direct widespread transfer of a gene to the related tissues. Attempts to modify muscle tissue have centered around fusion of implanted myocytes with host muscle $(11,12)$ or injection of DNA (13-15). Fusion in mice of normal donor muscle precursor cells with host mdx myofibers (11) has borne excitement leading to preliminary trials of such cell therapy in children. This approach 

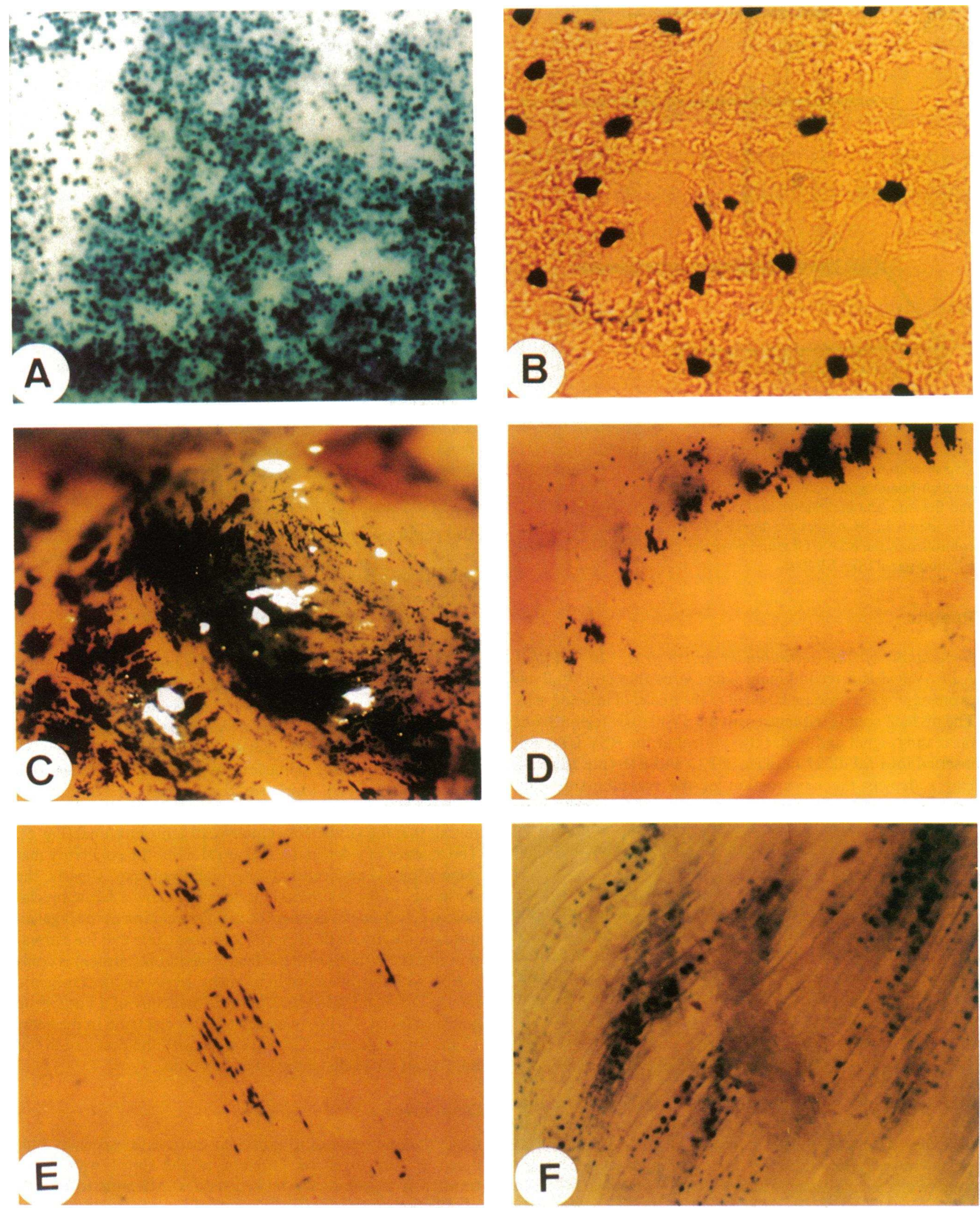

Figure 2. Efficient adenoviral-mediated gene transfer to mouse organs as evidenced by histochemical staining for $\beta$-galactosidase activity. $(A)$ Liver ( $\times 40)$; $(B)$ lung $(\times 400)$; $(C)$ heart atrium $(\times 40) ;(D)$ heart ventricle $(\times 40) ;(E)$ intestine $(\times 40)$; $(F)$ skeletal muscle $(\times 40)$. Newborn mice were injected intravenously and organs were removed $15 \mathrm{~d}$ after injection for in situ assay for $\beta$-galactosidase activity. 

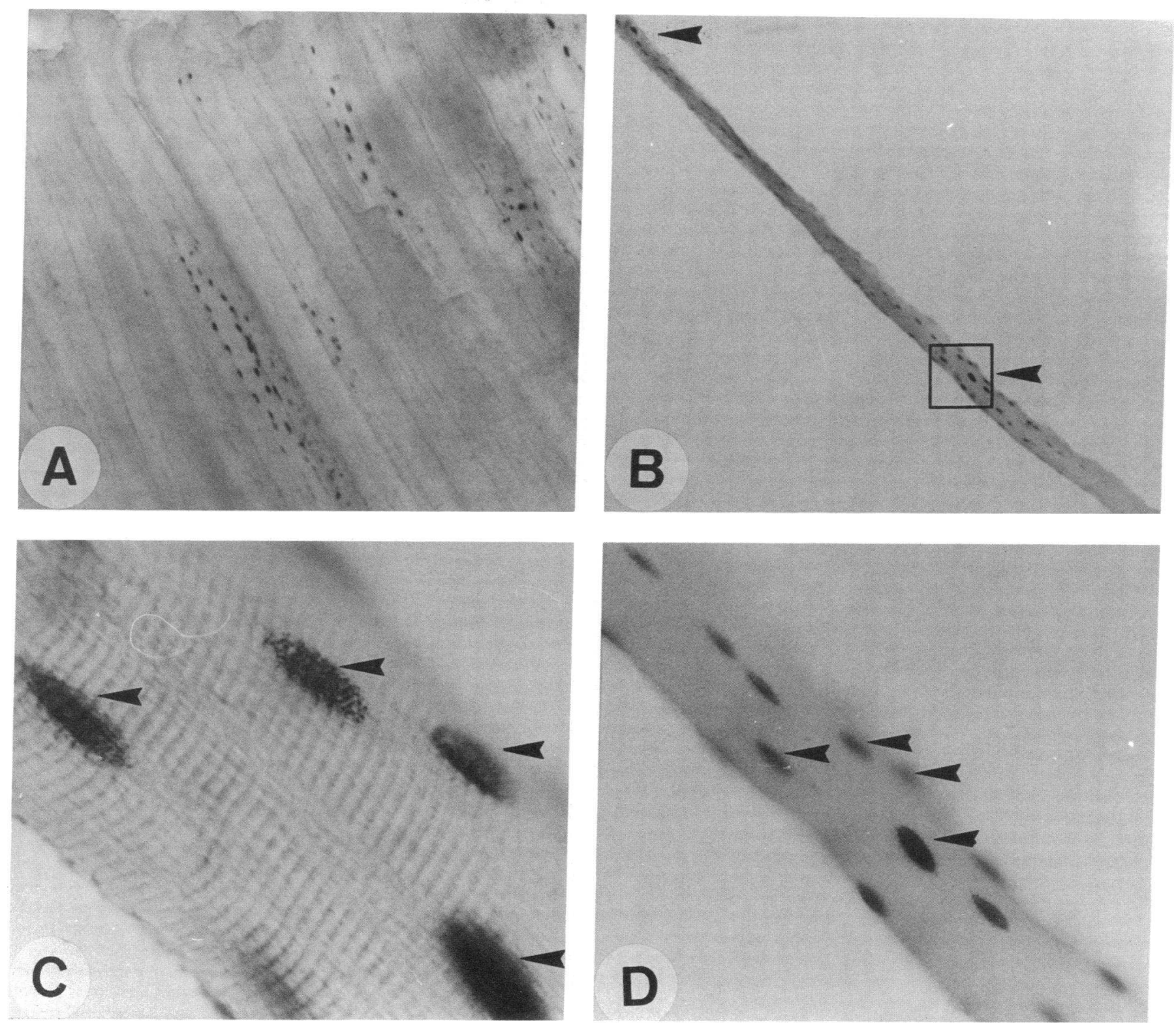

Figure 3. Detailed analysis of gene transfer into skeletal muscle after iv injection of Ad.RSV $\beta$ gal. Gene expression was assessed 5 mo after injection by histochemical staining for nuclear $\beta$-galactosidase activity. $(A)$ Dorsal skeletal muscle $(\times 40) ;(B)$ isolated dorsal muscle fiber $(\times 40)$. Arrowheads indicate two centers of expression. $(D)$ Enlargement of boxed area in $B(\times 250)$. A dark blue source nucleus is surrounded by nuclei of varying intensity of blue staining. $(C)$ Enlargement of center of expression shown in $D(\times 500)$. Arrowheads indicate source nucleus and nuclei of immediate vicinity.

may, nevertheless, have too many drawbacks for it to be applicable to the treatment of disease. As the migratory capacities of precursor cells are restricted to a few millimeters, cell implantation would necessitate millions of injections during hours of anesthesia. Inevitably, immunological problems would be encountered, as with any graft. Furthermore, large scale requirements for human myogenic cells constitute a practical limitation. In addition, the treatment of Duchenne muscular dystrophy (DMD) not only calls for therapy for skeletal muscles, but for myocardial cells too. It is difficult to envisage cell therapy as a means to provide relief to such an array of diseased cells.

The concept of somatic gene therapy will more than likely provide the most promising solution in the future. Importantly, its scope goes beyond the treatment of muscle disease, since it is applicable to a large number of genetic disorders. The direct introduction of purified nucleic acids into various organs in vivo is attractive due to its simplicity, but again, practical obstacles may limit its development. Furthermore, the resultant gene expression in muscle remains localized to the point of injection of DNA (13) and seems to be quite limited in duration, particularly in cardiac muscle (14). Interestingly, all other organs tested proved to be nonreceptive to DNA transfection. Thus, a method allowing a more widespread distribution of stable gene expression would be of invaluable importance to gene therapy in general.

The present report demonstrating the feasibility of adenovirus-mediated direct in vivo gene transfer into myocytes of mice has serious implications for treatment of muscular disorders, including heart diseases. The proportion of skeletal and myocardial cells expressing the transferred gene is more in keeping with that probably required for a reversal of disease state. It is 

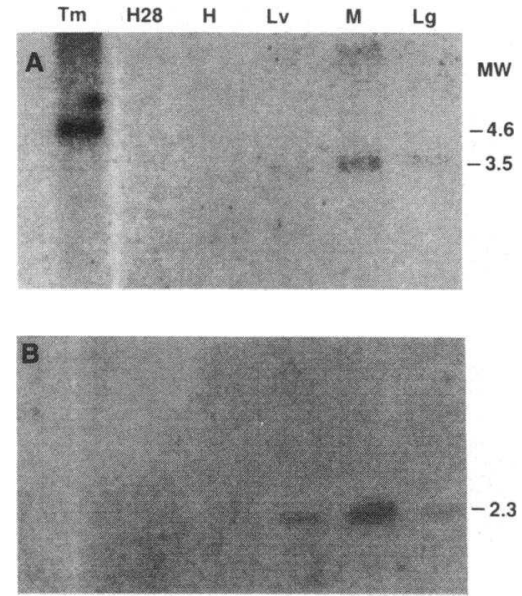

Figure 4. Southern blot analyses. All lanes contain $10 \mu \mathrm{g}$ of HindIIIdigested tissue DNA hybridized either with a Lac $\mathrm{Z}$ probe $(A)$ or with a probe specific for the left end of the recombinant virus $(B)$. Tm corresponds to the DNA of a transgenic mouse which contains one copy/cell of a Lac Z gene. DNA from the heart $(H)$, liver $(L v)$, skeletal muscle $(M)$, and lung $(L g)$ of a mouse killed at $10 \mathrm{~d}$ after injection were analyzed. $\mathrm{H} 28$ corresponds to heart DNA from a mouse killed 12 mo pi. Size markers $(M W)$ are shown in kilobasepairs in the right margin.

expected that the percentage of recipient cells be a function of the quantity of injected virus per animal weight. The possibility to obtain very high titers of adenovirus makes it conceivable to increase the input of virus for larger animals. The remarkable stability of expression observed (at least $12 \mathrm{mo}$ ), notwithstanding the extrachromosomal state of the vector, would be of safe therapeutic value.

An important distribution of the putative therapeutic DNA is a prerequisite for the treatment of muscular diseases like DMD. This can clearly be achieved when a recombinant adenovirus is administered intravenously since in this case dispersion of the vector occurs throughout the animal. In contrast, the direct intramuscular injection of a recombinant adenovirus can only lead to a localized gene transfer. It is noteworthy that gene transfer is successful not only in neonatal animals, but also in adults (albeit to a lesser extent), thus opening the route to gene therapy of diseases clinically diagnosed later in life.

Importantly, adenovirus can carry tissue-specific promoters, consequently restricting the actual sites of expression of the exogenous gene $(16,17)$. Moreover, the important cloning capacity of the adenovirus vector makes realistic and promising the construction of a recombinant adenovirus harboring the dystrophin gene. The recent report showing that expression of dystrophin can correct one of the effects of dystrophin deficiency (15), can only stress the urgency of an adapted vector. Taken together, the potentials of adenovirus along with its

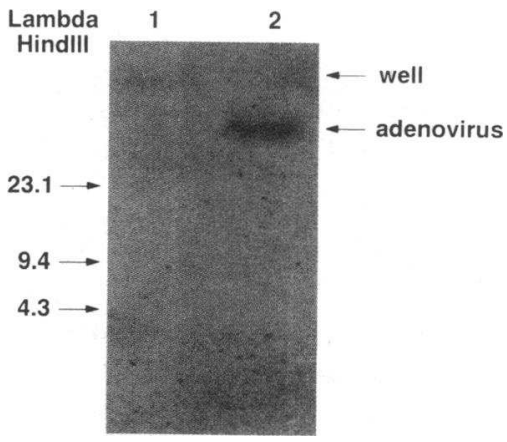

Figure 5. Southern blot analysis. Lane $1,10 \mu \mathrm{g}$ of undigested tissue DNA prepared from a control heart; lane 2 , $10 \mu \mathrm{g}$ of undigested tissue DNA prepared from the heart of an experimental mouse injected intravenously 3 mo previously. Size markers (Lambda/HindIII) are shown in kilobasepairs in the left margin, and arrows in the right margin indicate loading wells and adenovirus size marker. proven capacities, render this virus a most interesting gene delivery system for the treatment of the important hereditary human disease, DMD. The construction of an adenovirus harboring the dystrophin cDNA is now in progress in the laboratory. If such a virus is to be used in humans, safety aspects should be addressed concerning viral dissemination in the local environment. In this regard, it is noteworthy that no Ad.RSV $\beta$ gal virus could be detected in urine and fecal matter after intravenous inoculation of the recombinant adenovirus even though a nuclear Lac Z expression could be detected not only in the smooth muscle of the intestine (Fig. $2 E$ ), but also occasionally in a few epithelial cells of this organ (data not shown).

\section{Acknowledgments}

We thank A. Kahn for a critical discussion and revision of the manuscript. We thank V. Chevalier for typing the manuscript.

Our work was supported by grants from the Centre National de la Recherche Scientifique, the Institut National de la Santé et de la Recherche Médicale, and the Association Française contre les Myopathies.

\section{References}

1. Stratford-Perricaudet, L. D., M. Levrero, J.-F. Chasse, M. Perricaudet, and P. Briand. 1990. Evaluation of the transfer and expression in mice of an enzymeencoding gene using a human adenovirus vector. Hum. Gene Ther. 1:241-256.

2. Rosenfeld, M. A., W. Siegfried, K. Yoshimura, K. Yoneyama, M. Fukayama, L. E. Stier, P. K. Paakko, P. Gilardi, L. D. Stratford-Perricaudet, M. Perricaudet, et al. 1991. Adenovirus-mediated transfer of a recombinant $\alpha 1$-antitrypsin gene to the lung epithelium in vivo. Science (Wash. DC). 252:431-434.

3. Rosenfeld, M. A., K. Yoshimura, B. Trapnell, K. Yoneyama, E. Rosenthal, W. Dalemans, M. Fukayama, J. Bargon, L. Stier, L. D. Stratford-Perricaudet, et al. 1992. In vivo transfer of the human cystic fibrosis transmembrane conductance regulator gene to the airway epithelium. Cell. 68:143-155.

4. Ralston, E., and Z. W. Hall. 1989. Transfer of a protein encoded by a single nucleus to nearby nuclei in multinucleated myotubes. Science (Wash. DC). 244:1066-1069.

5. Kalderon, D., B. L. Roberts, W. D. Richardson, and A. E. Smith. 1984. A short amino acid sequence able to specify nuclear location. Cell. 39:499-509.

6. Bonnerot, C., D. Rocancourt, P. Briand, G. Grimber, and J.-F. Nicolas. 1987. A $\beta$-galactosidase hybrid protein targeted to nuclei as a marker for developmental studies. Proc. Natl. Acad. Sci. USA. 84:6795-6799.

7. Gluzman, Y., H. Reichl, and D. Solnick. 1982. Helper-free adenovirus type 5 vectors. In Eukaryotic Viral Vectors. Y. Gluzman, editor. Cold Spring Harbor Laboratory, Cold Spring Harbor, NY. pp. 187-192.

8. Graham, F. L., J. Smiley, W. C. Russel, and R. Nairu. 1977. Characteristics of a human cell line transformed by DNA from human adenovirus type 5. J. Gen. Virol. 36:59-72.

9. Shenk, T., and J. Williams. 1984. Genetic analysis of adenoviruses. Curr. Top. Microbiol. Immunol. 111:1-39.

10. Sambrook, J., E. F. Fritsch, and T. Maniatis. 1989. Molecular Cloning: A Laboratory Manual. 2nd ed. Cold Spring Harbor Laboratory Press, Cold Spring Harbor, NY.

11. Partridge, T. A., J. E. Morgan, G. R. Coulton, E. P. Hoffman, and L. M. Kunkel. 1989. Conversion of $\mathrm{mdx}$ myofibres from dystrophin-negative to -positive by injection of normal myoblasts. Nature (Lond.). 337:176-179.

12. Salminen, A., H. F. Elson, L. A. Mickley, A. T. Fojo, and M. M. Gottesman. 1991. Implantation of recombinant rat myocytes into adult skeletal muscle: a potential gene therapy. Hum. Gene Ther. 2:15-26.

13. Wolff, J. A., R. W. Malone, P. Williams, W. Chong, G. Acsadi, A. Jani, and P. L., Felgner. 1991. Direct gene transfer into mouse muscle in vivo. Science (Wash. DC). 247:1465-1468

14. Acsadi, G., S. Jiao, A. Jani, D. Duke, P. Williams, W. Chong, and J. A. Wolff. 1991. Direct gene transfer and expression into rat heart in vivo. New Biol. 3:71-81.

15. Acsadi, G., G. Dickson, D. R. Love, A. Jani, F. S. Walsh, A. Gurusinghe, J. A. Wolff, and K. E. Davies. 1991. Human dystrophin expression in mdx mice after intramuscular injection of DNA constructs. Nature (Lond.). 352:815-818

16. Friedman, J. M., L. E. Babiss, D. F. Clayton, and J. E. Darnell, Jr. 1986. Cellular promoters incorporated into the adenovirus genome: cell specificity of albumin and immunoglobulin expression. Mol. Cell. Biol. 6:3791-3797.

17. Karlsson, S., K. van Doren, S. Schweiger, A. Nienhuis, and Y. Gluzman. 1986. Stable gene transfer and tissue-specific expression of a human globin gene using adenoviral vectors. EMBO (Eur. Mol. Biol. Organ.) J. 5:2377-2385. 